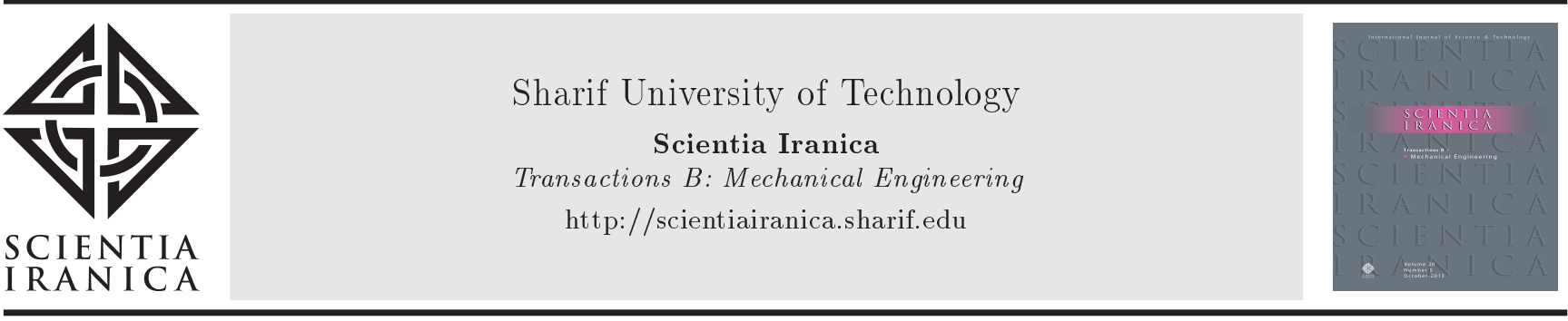

\title{
Effects of process parameters in gas tungsten arc welding of thin titanium plates
}

\author{
T.-T. Nguyen ${ }^{a, b, *}$ and V.-T. Pham ${ }^{b}$ \\ a. Institute of Research and Development, Duy Tan University, 03 Quang Trung, Da Nang, 550000, Vietnam. \\ b. Faculty of Mechanical Engineering, Le Quy Don Technical University, 236 Hoang Quoc Viet Street, Hanoi, 100000, Vietnam. \\ Received 17 June 2018; received in revised form 13 October 2018; accepted 31 December 2018
}

\author{
KEYWORDS \\ Gas tungsten arc \\ welding; \\ Titanium; \\ Tensile force; \\ Hardness; \\ Parameters; \\ Desirability approach.
}

\begin{abstract}
This work systematically explores the effects of process parameters on the technological responses, including Tensile Force (TF) and the Average Micro-Hardness (AMH), in Gas Tungsten Arc Welding (GTAW) of titanium. Process parameters are welding current $(I)$, gas flow rate $(F)$, and arc gap $(G)$. The objective of this work is to improve tensile strength with respect to micro-hardness constraints. GTAW welding machine was utilized with the Box-Behnken matrix to conduct experimental trails. The nonlinear relationships between welding parameters and responses were developed using Response Surface Method (RSM). Subsequently, an optimization technique, entitled Desirability Approach (DA), was used to analyze the trade-off among the considered responses and to find the optimal parameters. Conformity test was carried out in order to evaluate the accuracy of optimal values. The results showed that welding current had the greatest influence on the outputs among all factors. The measured improvements with optimal parameters of TF and AMH were approximately $4.10 \%$ and $6.12 \%$, respectively, in comparison with the initial setting. The hybrid approach comprising RSM and DA was found an effective method for obtaining significantly optimal values in GTAW processes.
\end{abstract}

(C) 2020 Sharif University of Technology. All rights reserved.

\section{Introduction}

Gas Tungsten Arc Welding (GTAW) is an effective joining technique in which the welded joint is prepared using tungsten electrode, the heated work-piece, and a filler under the protection of the shielding gas. The major capabilities of the GTAW process are producing high quality joints, applicability to a wide range of materials used, and proper functionality for thin sections. This process is widely adopted in the aerospace and automotive industries as well as the repairing fields for

*. Corresponding author. Tel.: +84982649266

E-mail address: trungthanhk21@mta.edu.vn (T.-T. Nguyen)

doi: $10.24200 /$ sci. 2018.51267 .2090 joining the thin sections of different materials. On the other hand, the primary shortcoming of the GTAW process is that it has the lowest deposition rate among all arc welding processes, which significantly influences the characteristics of the welded bead. Therefore, improving the technical outputs of GTAW processes is still an effective contribution and important research area.

Enhancing technological responses of the GTAW welding processes using optimum factors has been widely investigated in the previous works. Former researchers attempted to improve the characteristics of welded beads, including depth of penetration, width, and Heat Affected Zone (HAZ) [1-7]. In addition, mechanical characteristics of welded joints have been improved by means of optimal factors [7-15]. The 
parameters optimized are the processing conditions (voltage, current, speed, gas flow rate, and arc gap), characteristics of the electrode (diameter and material), and workpiece properties (thickness and material). It can be stated that multi-response optimization of welding processes is more complex and practical than single optimizing. However, the aforementioned works on GTAW welding processes still have the following deficiencies.

They focus on GTAW welding optimization of the stainless steel, magnesium alloys, and aluminum with dissimilar or similar joints. Optimization of welding parameters for improving mechanical properties, including Tensile Force (TF) and Average Micro-Hardness (AMH), of the titanium has not been considered yet, hence the deficiencies in welding of titanium.

Most of the previous researchers attempted to maximize micro-hardness of welded joints. However, in practice, excessive hardness could lead to a reduction in brittle strength, resulting in unfavorable quality.

The selection of optimal parameters may have inefficient results due to strong conflicts between tensile strength and hardness. It is necessary to resolve the natural contradiction between these two factors to achieve reliable optimum solutions for the welding performance.

To fill the mentioned research gap, multi-objective optimization of GTAW of grade- 2 titanium is considered in this paper for improving tensile strength with predefined micro-hardness. A hybrid approach combining RSM model and Desirability Approach (DA) is used to develop the predictive models and identify the globally optimal solution. This paper is an important contribution to the investigation into the impacts of welding parameters on TF and micro-hardness and it will help the welding operators to select appropriate conditions.

\section{Materials and methods}

The systematic procedure for titanium GTAW and welding parameter optimization is depicted in Figure 1. The Box-Behnken method was adopted in order to reduce experimental costs and ensure accuracy of modeling. Three key welding parameters were current $I$, gas flow rate $F$, and arc gap length $G$ and their levels are listed in Table 1. The factors were selected based on review of the literature on welding optimization, machine characteristics, and material properties. The ranges of parameters were taken based on welding settings normally followed in industries for the titanium material. The lowest level of each processing factor was selected to ensure sufficient melting, weld formation, and penetration. Additionally, the upper bound

Table 1. Control factors and their ranges.

\begin{tabular}{ccccc}
\hline \multirow{2}{*}{ Symbol } & Parameter & $\begin{array}{c}\text { Level } \\
\mathbf{- 1}\end{array}$ & $\begin{array}{c}\text { Level } \\
\mathbf{0}\end{array}$ & $\begin{array}{c}\text { Level } \\
\mathbf{+ 1}\end{array}$ \\
\hline$I$ & Current (A) & 70 & 130 & 200 \\
$F$ & Gas flow rate (L/min) & 12 & 16 & 20 \\
$G$ & Arc gap length $(\mathrm{mm})$ & 2 & 4 & 6 \\
\hline
\end{tabular}

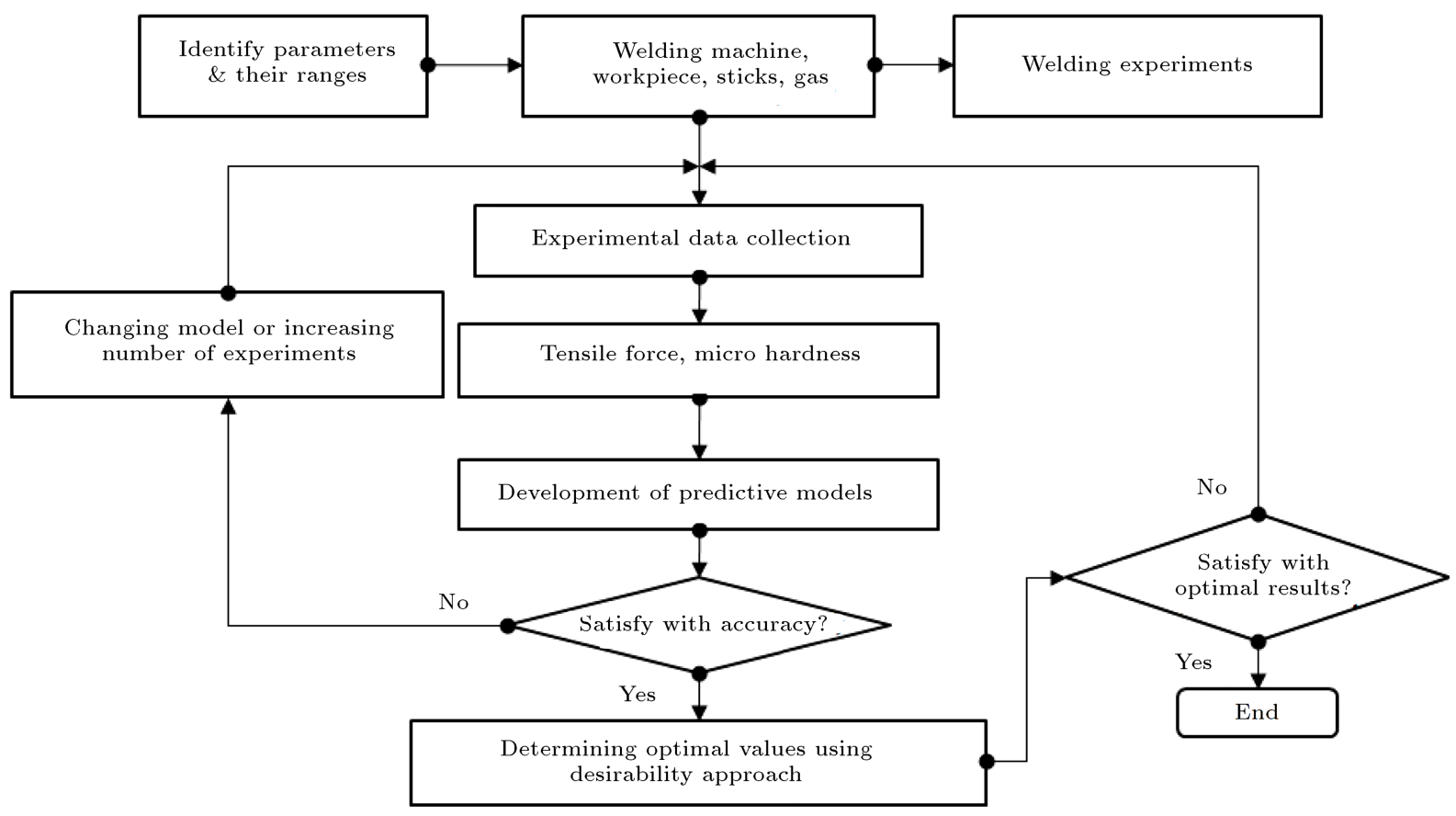

Figure 1. Optimization procedure. 
was determined to avoid excessive melting and crack formation. Furthermore, these values were verified by means of welding handbook and expert knowledge of the industry partner.

The output models for TF and AMH were developed with the aid of RSM [16-18] and experimental data. TF was used to measure the load required to stretch the welded specimen to the breaking point. The values of the TF were directly extracted from experimental results. ANOVA analysis was performed to investigate adequacy of the proposed models and significance of the parameters.

In this paper, an optimizing technique, entitled DA, is used in order to find the optimal values due to its simplicity and flexibility compared to other methods [19]. The main principle of the DA is to first convert each objective $y_{i}(x)$ into an individual desirability function $d_{i}\left(0 \leq d_{i} \leq 1\right)$. This method is based on the idea that a process or product which has multiple characteristics while one of them does not possess some desired value is completely unacceptable. The approach finds processing conditions in order to obtain the most desirable values of responses. The simultaneous objective is the geometric mean of all converted responses. A higher desirability function implies that the response is more desirable. In this study, the completely undesired objective was observed in case of $d_{i}=0$. On the other hand, completed desirability or ideal response was achieved in case of $d_{i}=1$. The characteristics of the response could be altered by adjusting the weights or importance. All targets were combined into one desirability function for multiple objectives and processing factors. The setting of optimal parameters was observed with maximum overall desirability value.

Desirability is calculated using Eq. (1) with the goal of maximizing:

$$
d_{i}= \begin{cases}0, & Y_{i} \leq L_{i} \\ \left(\frac{Y_{i}-L_{i}}{H_{i}-L_{i}}\right)^{w}, & L_{i}<Y_{i}<-H_{i} \\ 1, & Y_{i} \geq H_{i}\end{cases}
$$

It is also calculated using Eq. (2) with the goal of minimizing:

$$
d_{i}= \begin{cases}0, & Y_{i} \leq L_{i} \\ \left(\frac{H_{i}-Y_{i}}{H_{i}-L_{i}}\right)^{w}, & L_{i}<Y_{i}<-H_{i} \\ 1, & Y_{i} \geq H_{i}\end{cases}
$$

The desirability is calculated using Eq. (3) for the goal as a target:

$$
d_{i}= \begin{cases}\left(\frac{Y_{i}-L_{i}}{T_{i}-L_{i}}\right)^{w 1}, & L_{i}<Y_{i}<T_{i} \\ \left(\frac{Y_{i}-H_{i}}{T_{i}-H_{i}}\right)^{w 2}, & T_{i}<Y_{i}<H_{i} \\ 0, & \text { Otherwise }\end{cases}
$$

and it is calculated using Eq. (4) for the goal within the range:

$$
d_{i}= \begin{cases}1, & L_{i}<Y_{i}<H_{i} \\ 0, & \text { Otherwise }\end{cases}
$$

where $L_{i}, H_{i}, T_{i}$, and $w_{i}$ are the low value, high value, target value, and weight of the $i$ th response, respectively. The weight is used to emphasize the vital role of the bound and the goal $\left(0.1 \leq w_{i} \leq 10\right)$. A value of the weight greater than 1 denotes higher emphasis on the response and vice versa. When the value of the weight is equal to $1, d_{i}$ varies from 0 to 1 in a linear model.

The overall desirability function $(D)$ of multiple responses is measured using Eq. (5) in terms of individual desirability $d_{i}$. Each performance can be assigned an importance $r(0.1 \leq r \leq 10)$ relative to other objectives.

$$
D=\left(\begin{array}{c}
N \\
\prod d_{i}^{r_{i}} \\
i=1
\end{array}\right)^{1 / \sum r_{i}}
$$

where $N$ is the number of the responses measured.

Titanium of the second grade was utilized with heat treatment through normalization $\left(700^{\circ} \mathrm{C}\right.$ in $120 \mathrm{~min})$ and tempering $\left(550^{\circ} \mathrm{C}\right.$ in $\left.60 \mathrm{~min}\right)$. Chemical composition of the Base Material (BM) tested by Energy Dispersive X-ray Spectrometry (EDS) is shown in Table 2.

The material used in the experimental trials was titanium sheet of $3 \mathrm{~mm}$ thickness. Specimens of $60 \times 88 \times 3 \mathrm{~mm}^{3}$ were cut from the sheet. Welding sticks of $1.5 \times 6 \times 3 \mathrm{~mm}^{3}$ were made from the BM using Wire Electrical Discharge Machining (WEDM). Titanium plates and fillers were cleaned using acetone and soaked in alcohol of $90^{\circ}$ to remove the contaminants. The welding edge was prepared with all titanium plates of $90^{\circ}$ included angle and $1.5 \mathrm{~mm}$ root face.

Then, the experimental runs were performed using a design matrix combining three inputs generated

Table 2. Chemical composition of titan grade 2 .

\begin{tabular}{ccccccc}
\hline $\mathbf{A l}$ & $\mathbf{Z r}$ & $\mathbf{M o}$ & $\mathbf{V}$ & $\mathbf{S i}$ & $\mathbf{M n}$ & $\mathbf{C r}$ \\
\hline 0.004 & $<0.003$ & 0.0005 & $<0.001$ & 0.012 & $<0.001$ & 0.014 \\
\hline $\mathbf{N i}$ & $\mathbf{F e}$ & $\mathbf{C u}$ & $\mathbf{W}$ & $\mathbf{O}$ & $\mathbf{N}$ & $\mathbf{T i}$ \\
\hline 0.002 & 0.12 & 0.003 & $<0.002$ & 0.072 & $<0.002$ & 99.8 \\
\hline
\end{tabular}




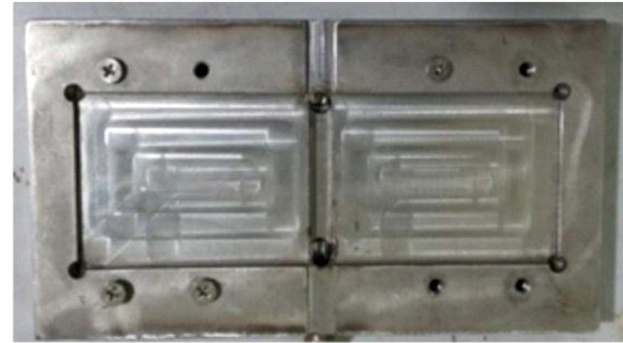

Welding fixture

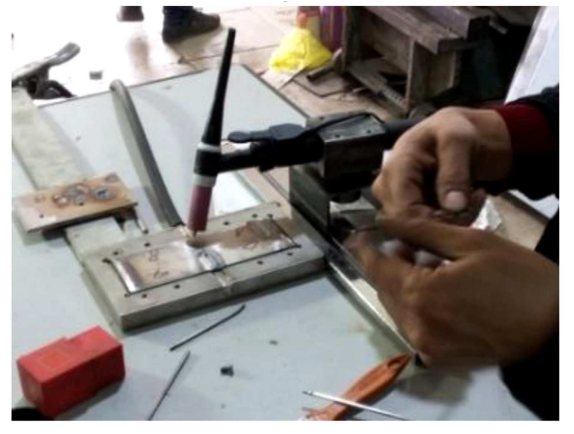

Welding torch

(a) Welding experiment

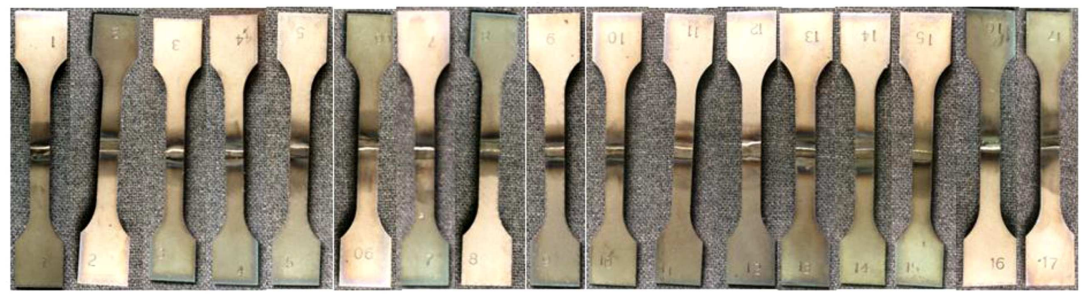

(b) Welded specimens
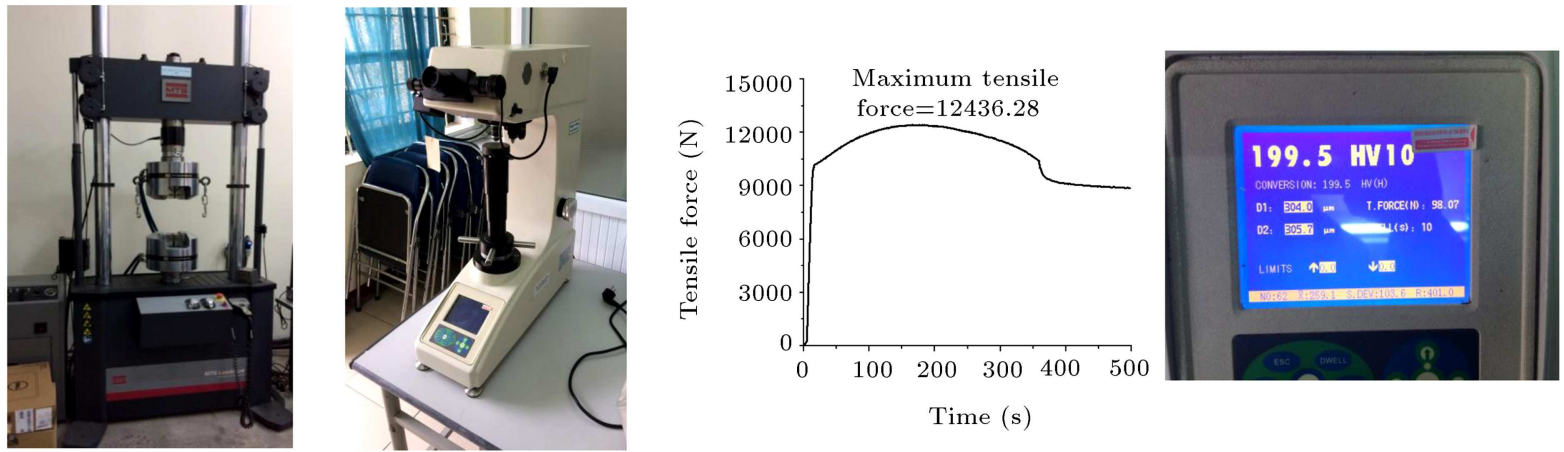

(c) Tensile and micro hardness testing

Figure 2. Experiments and measurements.

by the Box-Behnken method. The welding trials were conducted with the aid of a ZX7-200 welding machine having an electrode diameter of $3.2 \mathrm{~mm}$ and $60^{\circ}$ tip angle. The welding torch angle of $45^{\circ}$ was applied in order to minimize the root gap between the plates. A fixture was utilized to circulate the protecting air and avoid deformation of the welded plates, as shown in Figure 2(a). Argon controlled by a flowmeter was used as the shielding gas in order to protect the welding areas. Shrinkage deformation and residual stress could be ignored due to the small HAZ and focused heat input. Two welded layers were generated during processing time in order to enhance the joint quality.

After welding, the welded specimens were polished by means of emery paper from 80 grits to $1 \mathrm{~mm}$ and cleaned using alcohol containing $4 \%$ nitric acid. The welded specimens were cut with the aid of WEDM (Figure 2(b)).

Finally, the TF and micro-hardness tests were performed with the aid of Exceed E45 and Vickers Wolperts Wilson machines, respectively (Figure 2(c)). The average hardness values were observed at five different positions of the weld bead with a $3 \mathrm{~N}$ load in 15 s. A 3708 Carl Zeiss Microscope was employed to explore the micro structure at different welded areas.

The specimen machined by the wire cutting process was utilized to evaluate mechanical properties of the BM, as depicted in Figure 3(a). The TF of $17712.01 \mathrm{~N}$ and $\mathrm{AMH}$ of $250.4 \mathrm{HV}$ are displayed in Figure 3(b) and (c), respectively.

\section{Results and discussions}

The Design Of Experiment (DOE) matrix and experimental results of the welding trials are exhibited in Table 3 . $R^{2}$-values were used to evaluate accuracy of the predictive models. The $R^{2}$-values of the TF and AMH models are 0.9903 and 0.9921 , respectively. Additionally, the experimental data are distributed 


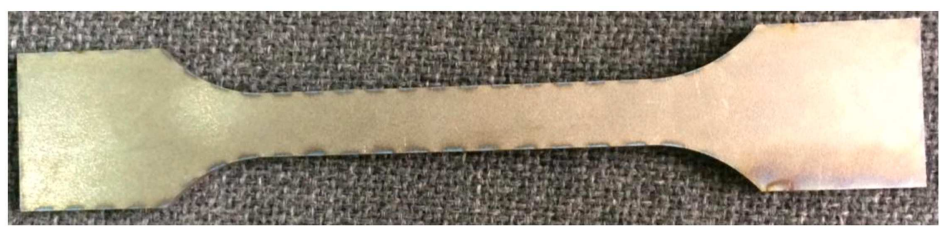

(a) Specimen of base material

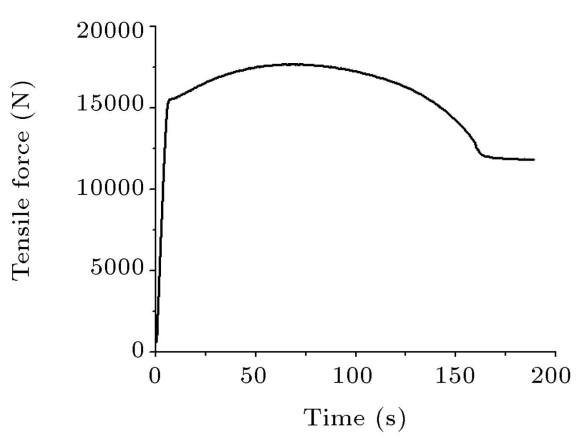

(b) Tensile strength of base material

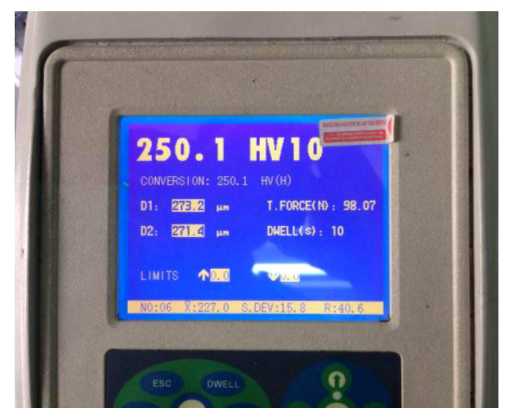

(c) Micro hardness of base material

Figure 3. Technological outputs of the Base Material (BM).

Table 3. Experimental results.

\begin{tabular}{cccccc}
\hline No. & $\begin{array}{c}\boldsymbol{I} \\
(\mathbf{A})\end{array}$ & $\begin{array}{c}\boldsymbol{F} \\
(\mathbf{L} / \mathbf{m i n})\end{array}$ & $\begin{array}{c}\boldsymbol{G} \\
(\mathbf{m m})\end{array}$ & $\begin{array}{c}\text { TF } \\
(\mathbf{N})\end{array}$ & $\begin{array}{c}\mathbf{A M H} \\
(\mathbf{H V})\end{array}$ \\
\hline 1 & 70 & 20 & 4 & 12550.32 & 202.7 \\
2 & 200 & 16 & 6 & 12840.48 & 224.4 \\
3 & 70 & 16 & 6 & 12148.26 & 191.2 \\
4 & 200 & 20 & 4 & 13148.28 & 234.2 \\
5 & 135 & 16 & 4 & 14210.54 & 247.8 \\
6 & 200 & 12 & 4 & 12072.65 & 202.4 \\
7 & 135 & 12 & 2 & 13797.36 & 237.7 \\
8 & 70 & 12 & 4 & 11398.68 & 167.4 \\
9 & 135 & 16 & 4 & 14207.62 & 248.2 \\
10 & 135 & 20 & 6 & 13065.48 & 222.6 \\
11 & 135 & 16 & 4 & 14208.48 & 248.4 \\
12 & 70 & 16 & 2 & 13276.08 & 222.2 \\
13 & 200 & 16 & 2 & 13944.24 & 255.5 \\
14 & 135 & 16 & 4 & 14208.24 & 247.6 \\
15 & 135 & 20 & 2 & 14571.12 & 258.8 \\
16 & 135 & 16 & 4 & 14209.52 & 246.5 \\
17 & 135 & 12 & 6 & 12436.28 & 199.5 \\
\hline & & & & &
\end{tabular}

on the straight lines and do not show any particular trend, as exhibited in Figure 4 . It can be stated that the predicted values highly correlate with experimental data. Therefore, accuracy of the RSM models proposed for the two welding performances is acceptable.

The significance and percentage contributions of welding parameters to the responses were analyzed using ANOVA. The factors with $p$-values less than 0.05 were considered as significant ones. The Pareto charts depicting parameter contributions for welding performances are shown in Figure 5.

As shown in Table $4, I, F, G, I^{2}$, and $F^{2}$ are significant terms for the TF model. Arc gap is the most affected factor with the highest contribution $(23.43 \%)$, followed by $F(11.88 \%)$ and $I(6.25 \%)$. All the interaction terms were considered as insignificant factors since their $p$ values were higher than $0.05 . I^{2}$ accounted for the highest percentage contribution among quadratic terms $(41.28 \%)$, followed by $F^{2}(17.11 \%)$.

The ANOVA results for AMH model are presented in Table 5 . In this model, the single terms ( $I$, $F, G)$ and quadratic terms $\left(I^{2}, F^{2}\right)$ were considered as the significant terms. $G$ was the most effective parameter with the highest contribution (21.87\%). The percentages of $I$ and $F$ were $20.76 \%$ and $14.54 \%$, respectively. Similarly, $I^{2}$ accounted for the highest percentage contribution, followed by $F^{2}$.

The predictive models of welding responses were developed with process parameters using RSM and experimental data. The regression coefficients of insignificant terms were eliminated based on ANOVA results. The regression response surface models showing TF and AMH are expressed as follows:

$$
\begin{gathered}
T F=-4419.7044+80.4964 I+1640.87619 F \\
-272.76092 G-0.27575 I^{2}-46.86019 F^{2} \\
A M H=-235.03565+1.98311 I+43.38245 F \\
\quad-13.10529 G-0.0061953 I^{2}-1.24063 F^{2}
\end{gathered}
$$

The main effects of each process parameter and their 


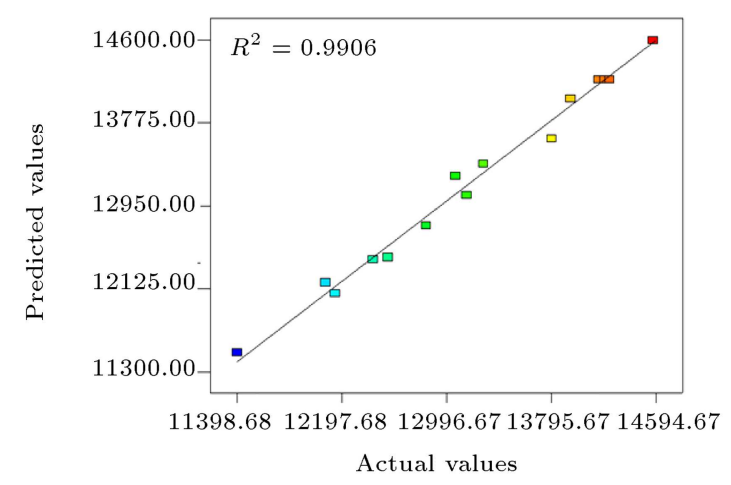

(a) For tensile force model

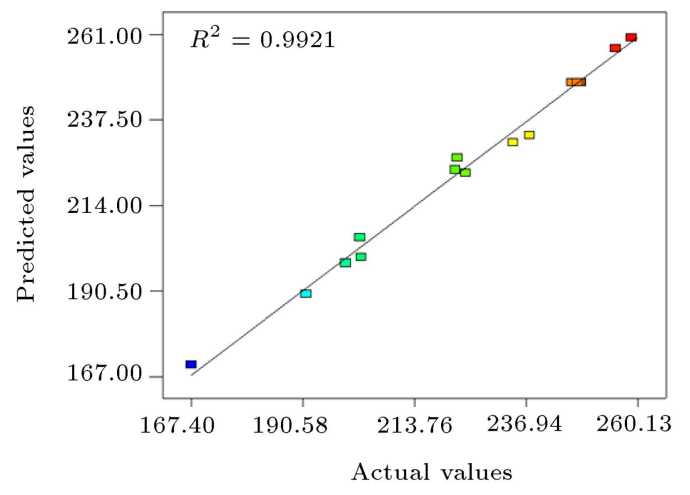

(b) For average micro hardness model

Figure 4. Investigation into the model accuracy.

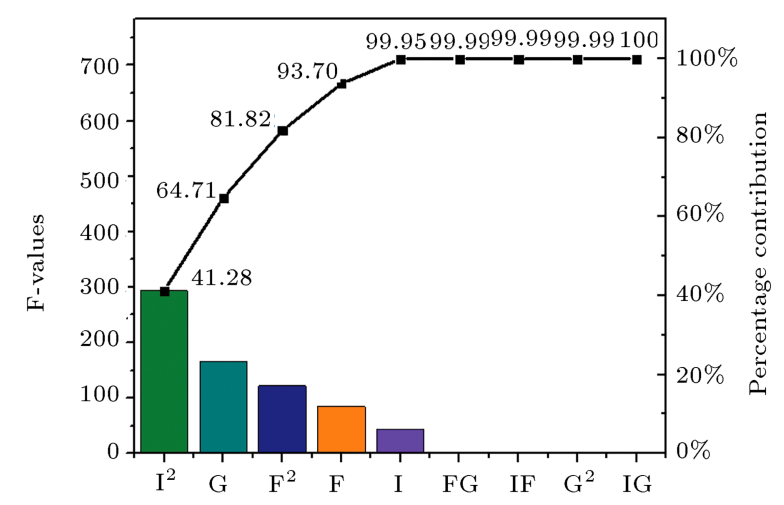

(a) For tensile force model

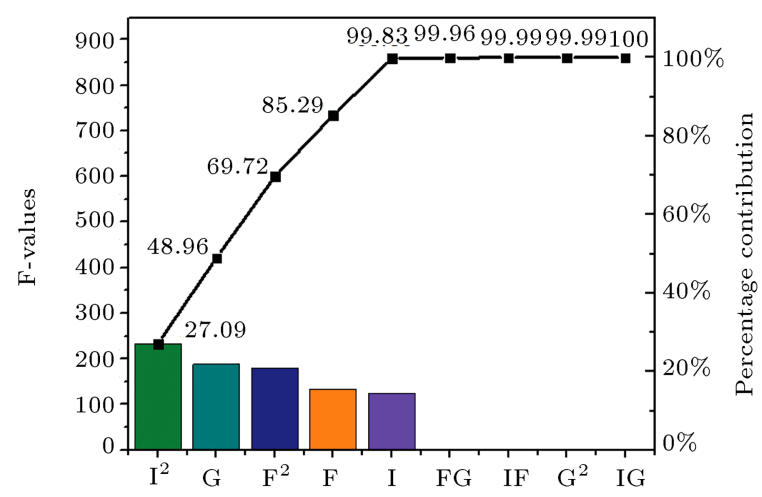

(b) For average micro hardness model

Figure 5. Pareto-charts for welding responses.

Table 4. ANOVA results for the Tensile Force (TF).

\begin{tabular}{ccccccc}
\hline Source & Sum of squares & Mean square & $\boldsymbol{F}$-value & $\boldsymbol{p}$-value & Remark & Contri. \\
\hline Model & 14315501.045704 & 1590611.227300 & 81.659829 & $<0.0001$ & Significant & - \\
$I$ & 866138.572800 & 866138.572800 & 44.466383 & 0.0003 & Significant & 6.25 \\
$F$ & 1647330.307200 & 1647330.307200 & 84.571710 & $<0.0001$ & Significant & 11.88 \\
$G$ & 3249108.352800 & 3249108.352800 & 166.804828 & $<0.0001$ & Significant & 23.43 \\
$I F$ & 1442.480400 & 1442.480400 & 0.074055 & 0.7934 & Insignificant & 0.01 \\
$I G$ & 145.443600 & 145.443600 & 0.007467 & 0.9336 & Insignificant & 0.00 \\
$F G$ & 5209.952400 & 5209.952400 & 0.267472 & 0.6210 & Insignificant & 0.04 \\
$I^{2}$ & 5722708.494017 & 5722708.494017 & 293.796114 & $<0.0001$ & Significant & 41.28 \\
$F^{2}$ & 2371978.176712 & 2371978.176712 & 121.774151 & $<0.0001$ & Significant & 17.11 \\
$G^{2}$ & 357.697217 & 357.697217 & 0.018364 & 0.8960 & Insignificant & 0.00 \\
\hline
\end{tabular}

interactions on the welding responses are shown in Figure 6.

As shown in Figure 6(a), TF is improved with increase in welding current. Low energy input was generated at low welding current, resulting in poor material mixing and weak weld. On the other hand, higher current increased the energy transferred to the base metal, leading to better fusion and improved mechanical strength. However, an increase in welding current or energy input resulted in a slower cooling rate and a coarser grain, leading to decreased TF.

Increase in gas flow rate up to the optimal value resulted in an improved TF and afterwards, the technical response started to decrease with the excessive flow rate (Figure 6(b)). Higher energy input was transferred to the BM at a low amount of gas flow rate, resulting in grain coarsening and decrease in TF. Increase in gas flow rate led to an improved TF. However, excessive 
Table 5. ANOVA results for the Average Micro-Hardness (AMH).

\begin{tabular}{ccccccc}
\hline Source & Sum of squares & Mean square & $\boldsymbol{F}$-value & $\boldsymbol{p}$-value & Remark & Contri. \\
\hline Model & 10882.455147 & 1209.161683 & 97.667755 & $<0.0001$ & Significant & - \\
$I$ & 2211.125000 & 2211.125000 & 178.599452 & $<0.0001$ & Significant & 20.76 \\
$F$ & 1548.461250 & 1548.461250 & 125.074037 & $<0.0001$ & Significant & 14.54 \\
$G$ & 2329.031250 & 2329.031250 & 188.123107 & $<0.0001$ & Significant & 21.87 \\
$I F$ & 3.062500 & 3.062500 & 0.247368 & 0.6342 & Insignificant & 0.03 \\
$I G$ & 0.002500 & 0.002500 & 0.000202 & 0.9891 & Insignificant & 0.00 \\
$F G$ & 1.000000 & 1.000000 & 0.080773 & 0.7845 & Insignificant & 0.01 \\
$I^{2}$ & 2884.760526 & 2884.760526 & 233.011091 & $<0.0001$ & Significant & 27.09 \\
$F^{2}$ & 1659.042105 & 1659.042105 & 134.005997 & $<0.0001$ & Significant & 15.58 \\
$G^{2}$ & 13.642105 & 13.642105 & 1.101915 & 0.3287 & Insignificant & 0.13 \\
\hline
\end{tabular}

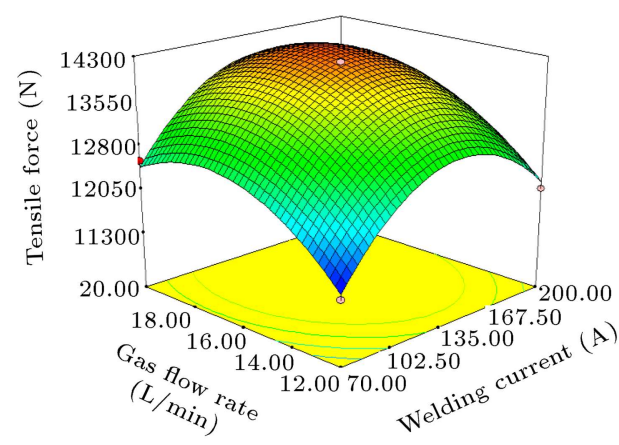

(a) Tensile force vs. current and gas flow rate

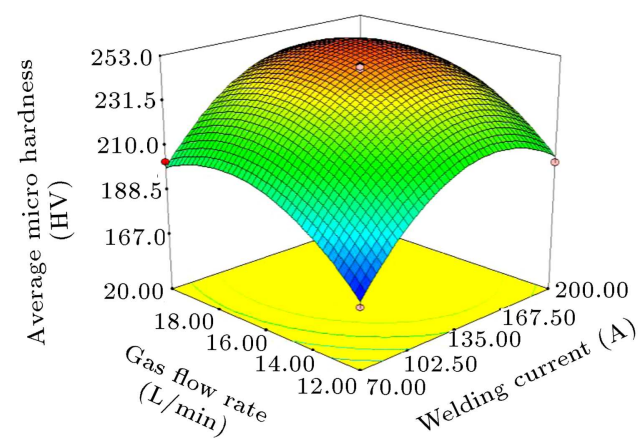

(c) Micro hardness vs. current and gas flow rate

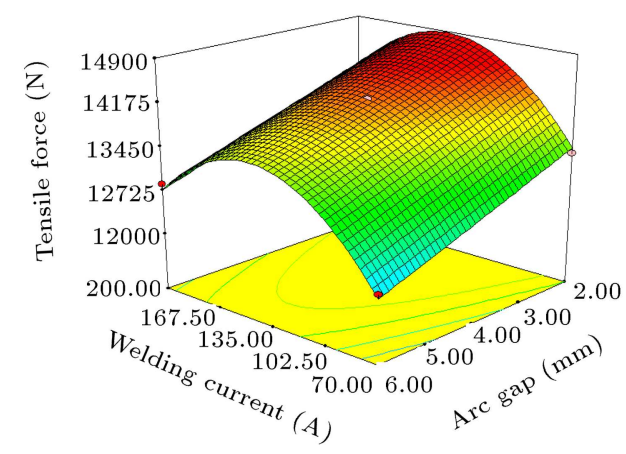

(b) Tensile force vs. arc gap and gas flow rate

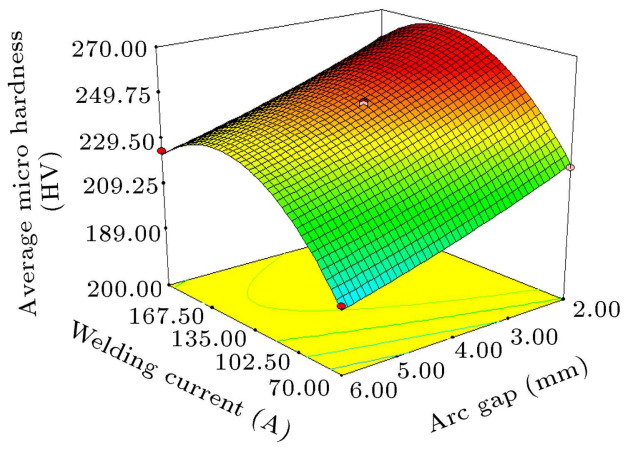

(d) Micro hardness vs. arc gap and gas flow rate

Figure 6. Effects of parameters on welding responses.

gas flow rate was associated with low energy input, which resulted in faster cooling rates of the weld and reduction in $\mathrm{TF}$.

As shown in Figure 6(b), as the arc gap increases, TF decreases due to lower input energy transferred to the BM. The heat input has an inverse proportion to the welding gap length. Therefore, TF could be minimized by increasing the arc gap.

Similarly, the impacts of processing factors on the AMH are shown in Figure 6(c) and (d).

The objective of this paper is to improve the welding responses, including $\mathrm{TF}$ and $\mathrm{AMH}$, through process parameter optimization. The optimizing problem can be defined as follows:

Find $X=[I, F, G]$;

Maximize TF;

Maximize AMH;

Constraints: $70 \leq I \leq 200$ (A), $12 \leq F \leq 20$ $(\mathrm{L} / \mathrm{min}), 2 \leq G \leq 6(\mathrm{~mm})$.

The design expert V7.0 software integrating the DA theory was used to determine the optimal parameters. The ranges and goals of independent variables 
Table 6. Parameters for desirability function in simultaneous optimization.

\begin{tabular}{lcccccc}
\hline \multicolumn{1}{c}{ Parameter } & Goal & $\begin{array}{c}\text { Lower } \\
\text { limit }\end{array}$ & $\begin{array}{c}\text { Upper } \\
\text { limit }\end{array}$ & $\begin{array}{c}\text { Lower } \\
\text { weight }\end{array}$ & $\begin{array}{c}\text { Upper } \\
\text { weight }\end{array}$ & Importance \\
\hline Welding current, $I$ & Is in range & 70 & 200 & 1 & 1 & 3 \\
Gas flow rate, $F$ & Is in range & 12 & 20 & 1 & 1 & 3 \\
Arc gap, $G$ & Is in range & 2 & 6 & 1 & 1 & 3 \\
Tensile Force (TF) & Maximize & 11398.7 & 14571.0 & 1 & 1 & 3 \\
Average Micro Hardness $(\mathrm{AMH})$ & Maximize & 167.4 & 258.8 & 1 & 1 & 3 \\
\hline
\end{tabular}

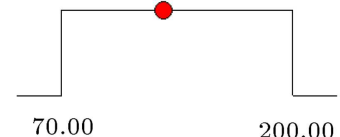

Welding current $I=127.83$

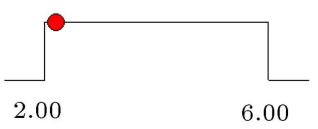

Arc gap $G=2.21$

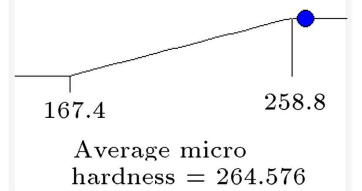

(a) Ramp graphs of process parameters and welding responses

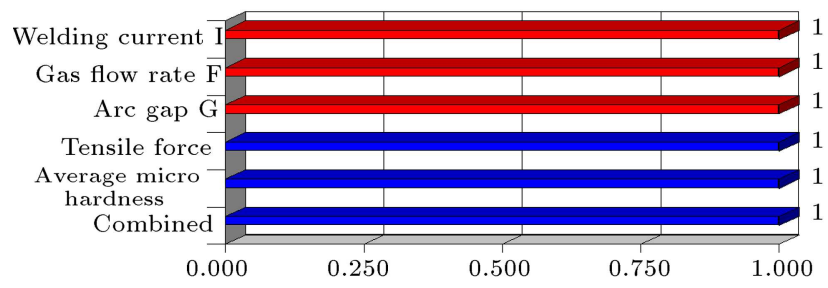

(b) Desirability graph

Figure 7. Optimization results using Desirability

Approach (DA).

and responses for simultaneous optimization of TF and AMH are shown in Table 6 . The ramp graphs of process parameters and welding responses using desirability function are shown in Figure 7(a). Figure 7(b) presents the desirability graph in terms of process parameters and technological performances with a combination of one. The optimal parameters and welding responses can be found in Table 7 .
Practically, it is unnecessary to simultaneously maximize two objectives, which can be a technical constraint. A higher micro-hardness could result in a reduction in brittle strength, leading to unacceptable weld quality. Furthermore, it can be stated that it is hard to determine the optimal welding parameters for different technological outputs based on practical experience or operating guide. As a result, the approach proposed can be adopted to determine the maximum TF and optimal welding parameters with predefined micro-hardness. The ranges and goals of independent variables and responses for the constrained optimization are shown in Table 8, in which $\mathrm{AMH}$ is predefined as a target. The constrained values are $230 \mathrm{HV}$, $204 \mathrm{HV}, 250 \mathrm{HV}$, and $255 \mathrm{HV}$, respectively. The representative scenarios with the constrained microhardness are given in Table 9.

An investigation was performed in order to confirm optimum results. A welded specimen prepared using optimal values was used, as depicted in Figure 8(a). The initial and optimized parameters are compared in Figure $8(\mathrm{~b})$ and (c). The small error indicates that the proposed approach is more effective and reliable in modeling and optimizing welding processes.

The microstructures of different welding areas, including the BM, HAZ, and Welded Zone (WZ) were investigated and they are exhibited in Figure 9. Figure 9(a) shows the evenly fine grain with the approximate size of $10 \mu \mathrm{m}$ in the BM. The HAZ with coarser grain and uneven size was observed without defects, e.g., voids and pits, as displayed in Figure 9(b). Grain size in the HAZ was around $120 \mu \mathrm{m}$ due to the welding heat. The microstructure of the $\mathrm{WZ}$ with large particles and irregular dimensions compared to the previous areas is shown in Figure 9(c). Grain size in the $\mathrm{WZ}$ was around $160 \mu \mathrm{m}$.

The element distribution in the welded joint

Table 7. Optimization results.

\begin{tabular}{cccccccc}
\hline \multicolumn{3}{c}{ Optimization parameters } & & \multicolumn{2}{c}{ Responses } \\
\cline { 1 - 3 } Method & $\boldsymbol{I}(\mathbf{A})$ & $\boldsymbol{F}(\mathbf{L} / \mathbf{m})$ & $\boldsymbol{G}(\mathbf{m m})$ & & TS $(\mathbf{N})$ & AMH $(\mathbf{H V})$ \\
\hline DA & 127.83 & 17.26 & 2.21 & & 14815.70 & 264.6 \\
Initial & 135 & 16 & 4 & & 14208.48 & 248.4 \\
Improvement $(\%)$ & & & & 4.10 & 6.12 \\
\hline
\end{tabular}


Table 8. Parameters for desirability function in the constrained optimization.

\begin{tabular}{lcccccc}
\hline \multicolumn{1}{c}{ Parameter } & Goal & $\begin{array}{c}\text { Lower } \\
\text { limit }\end{array}$ & $\begin{array}{c}\text { Upper } \\
\text { limit }\end{array}$ & $\begin{array}{c}\text { Lower } \\
\text { weight }\end{array}$ & $\begin{array}{c}\text { Upper } \\
\text { weight }\end{array}$ & Importance \\
\hline Welding current, $I$ & Is in range & 70 & 200 & 1 & 1 & 3 \\
Gas flow rate, $F$ & Is in range & 12 & 20 & 1 & 1 & 3 \\
Arc gap, $G$ & Is in range & 2 & 6 & 1 & 1 & 3 \\
Tensile Force (TF) & Maximize & 11398.7 & 14571.0 & 1 & 1 & 3 \\
Average Micro Hardness (AMH) & $\begin{array}{c}\text { Target }=230,240, \\
250, \text { and } 255\end{array}$ & 167.4 & 258.8 & 1 & 1 & 3 \\
\hline
\end{tabular}

Table 9. Representative scenarios with the constrained values of micro-hardness.

\begin{tabular}{|c|c|c|c|c|c|}
\hline \multirow{2}{*}{ Scenario } & \multicolumn{3}{|c|}{ Optimization parameters } & \multirow{2}{*}{$\begin{array}{c}\text { Tensile Force }(\mathrm{TF}) \\
\text { TF }(\mathrm{N})\end{array}$} & \multirow{2}{*}{$\begin{array}{r}\text { Constraint } \\
\text { AMH (HV) } \\
\end{array}$} \\
\hline & $I(\mathbf{A})$ & $F(\mathbf{L} / \mathbf{m})$ & $G(\mathrm{~mm})$ & & \\
\hline 1 & 100.88 & 14.81 & 3.52 & 13662.34 & 230 \\
\hline 2 & 103.72 & 15.67 & 3.14 & 14011.58 & 240 \\
\hline 3 & 108.17 & 16.37 & 2.63 & 14353.72 & 250 \\
\hline 4 & 110.21 & 16.79 & 2.33 & 14521.01 & 255 \\
\hline
\end{tabular}

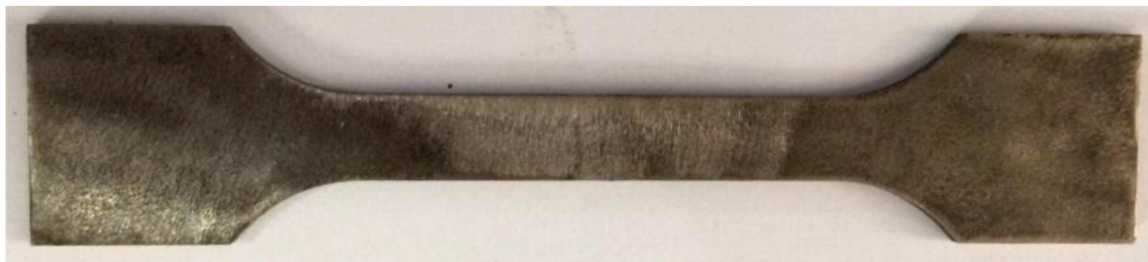

(a) Welded specimen for testing accuracy of optimum result

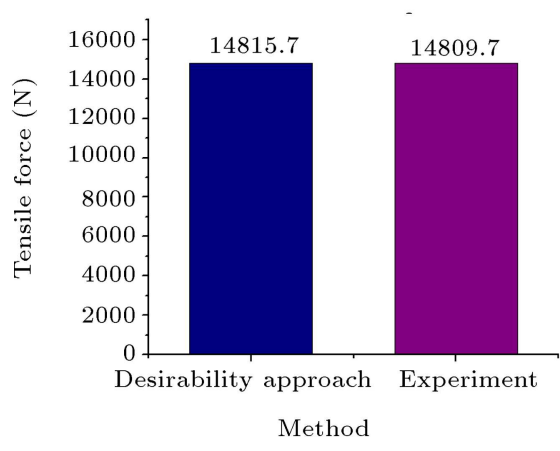

(b) Comparison for tensile force

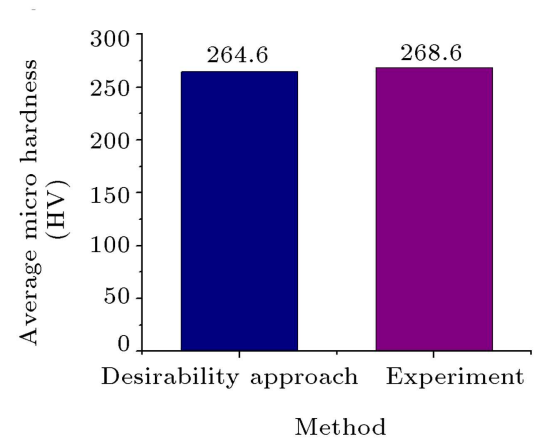

(c) Comparison for micro hardness

Figure 8. Experimental confirmation.

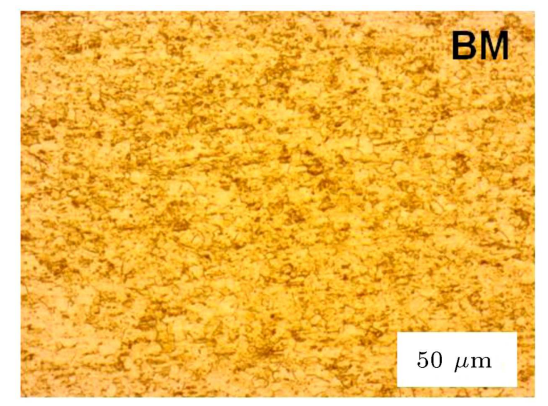

(a) Microstructure of Base Material (BM)

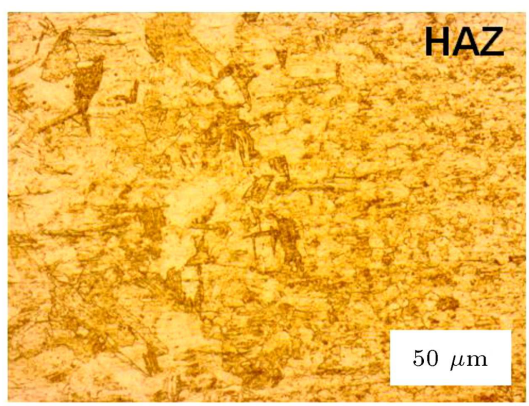

(b) Microstructure of the interface zone

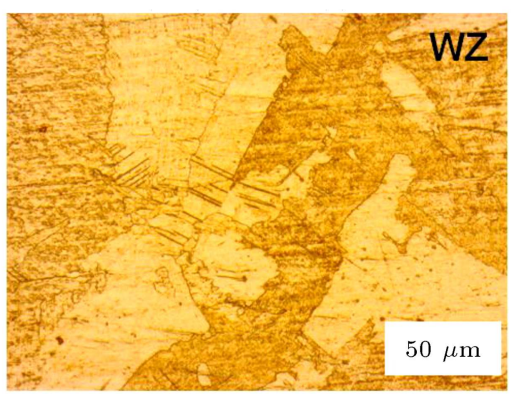

(c) Microstructure of the Welded Zone (WZ)

Figure 9. Microstructure of the welded joint. 
Table 10. Chemical composition of the welded joint.

\begin{tabular}{ccccccc}
\hline $\mathbf{A l}$ & $\mathbf{Z r}$ & $\mathbf{M o}$ & $\mathbf{V}$ & $\mathbf{S i}$ & $\mathbf{M n}$ & $\mathbf{C r}$ \\
\hline 0.005 & 0.004 & $<0.0003$ & $<0.001$ & 0.012 & $<0.001$ & 0.013 \\
\hline $\mathbf{N i}$ & $\mathbf{F e}$ & $\mathbf{C u}$ & $\mathbf{W}$ & $\mathbf{O}$ & $\mathbf{N}$ & $\mathbf{T i}$ \\
\hline 0.002 & 0.12 & 0.001 & $<0.002$ & 0.12 & $<0.002$ & 99.7 \\
\hline
\end{tabular}

explored using EDS is presented in Table 10. The result indicates that the chemical compositions between BM and welded joint are the same due to using the titanium filler.

\section{Conclusions}

This work presented multi-response optimization of process parameters in the Gas Tungsten Arc Welding (GTAW) process to improve Tensile Force (TF) while micro-hardness was considered as a constraint. Models developed by the Response Surface Method (RSM) were used in conjunction with the Desirability Approach (DA) to render the nonlinear relations between inputs and technological outputs as well as to determine the optimal values. The main conclusions from the results of this work by the parameters considered can be drawn as follows:

1. $\mathrm{TF}$ and Average Micro-Hardness (AMH) values improved with increase in welding current or gas flow rate until reaching the optimal points and afterwards, with higher factors, the technological outputs decreased. Additionally, the highest technological performances were observed at the lowest level of the arc gap;

2. The optimal process parameters were the welding current of $127.83 \mathrm{~A}$, gas flow rate of $17.26 \mathrm{~s}$, and arc gap of $2.21 \mathrm{~mm}$. Arc gap had the greatest influence on the mechanical strength of the welded joint, followed by gas flow rate and welding current. For micro-hardness, arc gap had the most effective contribution, followed by current and gas flow rate;

3. Solving the multi-objective optimization problem using DA could ensure achieving reliable optimizing values. The proposed approach to improving tensile strength with predefined micro-hardness was versatile and realistic in the welding processes compared with single-objective or simultaneous two response optimization.

\section{Acknowledgment}

This research was funded by Vietnam National Foundation for Science and Technology Development (NAFOSTED) under grant number 107.04-2017.06.

\section{References}

1. Kurtulmus, M. "Effects of welding parameters on penetration depth in mild steels A-TIG welding", Sci. Iran., 26(3), pp. 1400-1404 (2019). DOI: 10.24200/SCI.2018.20145.

2. Moghaddam, M.A., Golmezerji, R., and Kolahan, F. "Simultaneous optimization of joint edge geometry and process parameters in gas metal arc welding using integrated ANN - PSO approach", Sci. Iran., 24(1), pp. 260-273 (2017).

3. Pamnani, R., Vasudevan, M., Jayakumar, T., and Vasantharaja, P. "Development of activated flux, optimization of welding parameters and characterization of weld joint for DMR-249A shipbuilding steel", Trans Indian Inst. Met., 70(1), pp. 49-57 (2017).

4. Chandrasekar, G., Kailasanathan, C., Verma, D.K., and Nandagopal, K. "Optimization of welding parameters, influence of activating flux and investigation on the mechanical and metallurgical properties of activated TIG weldments of AISI $316 \mathrm{~L}$ stainless steel", Trans Indian Inst. Met., 70(3), pp. 671-684 (2017).

5. Korra, N.N., Vasudevan, M., and Balasubramanian, K.R. "Optimization of A-TIG welding of duplex stainless steel alloy 2205 based on response surface methodology and experimental validation", Proc. Inst. Mech. Eng. Pt. L J. Mater. Des. Appl., 230(4), pp. 837-864 (2016).

6. Pamnani, R., Vasudevan, M., Vasantharaja, P., and Jayakumar, T. "Optimization of A-GTAW welding parameters for naval steel (DMR 249 A) by design of experiments approach", Proc. Inst. Mech. Eng. Pt. L J. Mater. Des. Appl., 231(3), pp. 320-331 (2017).

7. Vidyarthy, R.S. and Dwivedi, D.K. "Activating flux tungsten inert gas welding for enhanced weld penetration", J. Manuf. Process, 22, pp. 211-228 (2016).

8. Bhattacharya, A. and Singla, S. "Dissimilar GTAW between AISI 304 and AISI 4340 steel: Multi-response optimization by analytic hierarchy process", Proc. Inst. Mech. Eng. E, 231(4), pp. 824-835 (2017).

9. Vasantharaja, P. and Vasudevan, M. "Optimization of A-TIG welding process parameters for RAFM steel using response surface methodology", Proc. Inst. Mech. Eng. Pt. L J. Mater. Des. Appl., 232(2), pp. 121-136 (2018).

10. Vidyarthy, R.S., Dwivedi, D.K., and Muthukumaran, V. "Optimization of A-TIG process parameters using response surface methodology", Mater Manuf. Proces, 33(7), pp. 709-717 (2018).

11. Ahmadi, E. and Ebrahimi, A.R. "Welding of $316 \mathrm{~L}$ austenitic stainless steel with activated tungsten inert gas process", J. Mater. Eng. Perform., 24(2), pp. 1065-1071 (2015).

12. Joseph, J. and Muthukumaran, S. "Optimization of activated TIG welding parameters for improving weld joint strength of AISI 4135 PM steel by genetic algorithm and simulated annealing", Int. J. Adv. Manuf. Technol., 93(1-4), pp. 23-34 (2017).

13. Pichumani, S., Srinivasan, R., and Ramamoorthi, V. "Mechanical properties, thermal profiles, and microstructural characteristics of $\mathrm{Al}-8 \% \mathrm{SiC}$ composite 
welded using pulsed current TIG welding", J. Mech. Sci. Technol., 32(8), pp. 1713-1723 (2018).

14. Vidyarthy, R.S., Dwivedi, D.K., and Vasudevan, M. "Influence of M-TIG and A-TIG welding process on microstructure and mechanical behavior of 409 ferritic stainless steel", J. Mater. Eng. Perform., 26(3), pp. 1391-1403 (2017).

15. Shen, J., Li, S., Zhai. D., Wen, L., Liu, K., and Dai, Y. "Effects of $\mathrm{SiC}$ on the Strengthening Activated Tungsten Inert Gas (SA-TIG) welded of magnesium alloy", Mater Manuf Proces, 28(11), pp. 1240-1247 (2013).

16. Goyal, A. and Garg, R.K. "Modeling and optimization of friction stir welding parameters in joining 5086 H32 aluminium alloy", Sci. Iran, 26(4), pp. 2407-2417 (2019). DOI: $10.24200 /$ SCI.2018.5525.1325

17. Mir Mohammad Hosseini, F., Ebadi, T., Eslami, A., et al. "Investigation of geotechnical properties of clayey soils contaminated with gasoil using Response Surface Methodology (RSM)", Sci. Iran, 26(3), pp. 1122-1134 (2019). DOI: $10.24200 /$ SCI.2017.4574
18. Tang, L.N., Ma, Y.Z., Wang, J.J., et al. "Robust parameter design of supply chain inventory policy considering the uncertainty of demand and lead time", Sci. Iran, 26(5), pp. 2971-2987 (2018). DOI: 10.24200/SCI.2018.5205.1217

19. Rajakumar, S. and Balasubramanian, V. "Diffusion bonding of titanium and AA 7075 aluminum alloy dissimilar joints-process modeling and optimization using desirability approach", Int. J. Adv. Manuf. Technol., 86(1-4), pp. 1095-1112 (2016).

\section{Biographies}

Trung-Thanh Nguyen received his PHD degree from University of Ulsan, South Korea, in 2016. His research interests include multi-objective optimization, energy efficiency of manufacturing process, $\mathrm{CAD} / \mathrm{CAM} / \mathrm{CNC} / \mathrm{CAE}$, and digital twins technology.

Van-Truong Pham received his MSc degree from Le Quy Don Technical University, Vietnam, in 2017. His research interest is optimization of welding processes. 